\title{
Understanding the dispersion and assembly of Bacterial Cellulose in Organic Solvents
}

Auren Ferguson ${ }^{1}$, Umar Khan ${ }^{1}$, Melissa Walsh ${ }^{2}$, Koon-Yang Lee ${ }^{3}$, Alexander Bismarck ${ }^{4,5}$, Milo S.P. Shaffer ${ }^{2}$, Jonathan N. Coleman ${ }^{1}$, Shane D. Bergin ${ }^{1}$

1. School of Physics and CRANN, Trinity College Dublin, Dublin 2, Ireland.

2. Department of Chemistry, Imperial College London, South Kensington Campus, London SW7 2AZ, United Kingdom.

3. The Composites Centre, Department of Aeronautics, Imperial College London, South Kensington Campus, London, SW7 2AZ, United Kingdom

4. Polymer and Composite Engineering (PaCE) Group, Department of Chemical Engineering, Imperial College London, South Kensington Campus, SW7 2AZ, United Kingdom

5. Polymer and Composite Engineering (PaCE) Group, Institute of Materials Chemistry and Research, Faculty of Chemistry, University of Vienna, Währingerstr. 42, A-1090, Austria

Keywords: Bacterial cellulose, liquid phase exfoliation, inverse gas chromatography, bacterial cellulose films, surface energy.

\begin{abstract}
The constituent nano-fibrils of bacterial cellulose are of interest to many researchers because of their purity and excellent mechanical properties. Mechanisms to disrupt the network structure of bacterial cellulose $(\mathrm{BC})$ to isolate bacterial cellulose nanofibrils $(\mathrm{BCN})$ are limited. This work focuses on liquid-phase dispersions of $\mathrm{BCN}$ in a range of organic solvents. It builds on work to disperse similarly intractable nanomaterials, such as single-walled carbon nanotubes, where optimum dispersion is seen for solvents whose surface energies are close to
\end{abstract}


the surface energy of the nanomaterial; bacterial cellulose is shown to disperse in a similar fashion. Inverse gas chromatrogrphy was used to determine the surface energy of bacterial cellulose, under relevant conditions, by quantifying the surface heterogeneity of the material as a function of coverage. Films of pure $\mathrm{BCN}$ were prepared from dispersions in a range of solvents; the extent of $\mathrm{BCN}$ exfoliation is shown to have a strong effect on the mechanical properties of $\mathrm{BC}$ films, and to fit models based on the volumetric density of nanofibril junctions. Such control offers new routes to producing robust cellulose films of bacterial cellulose nanofibrils.

\section{Introduction}

Bacterial cellulose (BC) is a biopolymer of ringed glucose molecules that is secreted by species of bacteria such as Acetobacter xylinum. ${ }^{1}$ During growth, adjacent molecules of cellulose aggregate through hydrogen bonding and van der Waals interactions into nanofibrils. ${ }^{2}$ Bacterial cellulose nanofibrils $(\mathrm{BCN})$ are ribbon-shaped, with widths and thicknesses on the order of 6-10 nm, and lengths of several micrometres. ${ }^{3}$ Structurally, BCN consist of stiff crystalline regions joined by more disordered amorphous segments, where the disordered domains form weak spots along a nanofibril. ${ }^{4}$ Young's moduli of individual BCN have been reported ${ }^{4-7}$ to be as high as 78-160 GPa. Excellent mechanical properties and high water-holding capacity make BCN appealing for a variety of applications. ${ }^{8}$ Furthermore, its ultra-fine reticulated structure lends itself to applications including composite membranes, ${ }^{9,10}$ artificial skin and medicine. $3,8,11,12$ Whilst the physical properties of BCN are extremely promising, their potential has been limited by their tendency to aggregate ${ }^{4}$ through inter-BCN bonds to form larger and weaker fibres, typically $\sim 100 \mathrm{~nm}$ wide. ${ }^{13}$ The combination of intraand inter-BCN bonding results in a stable hierarchical biopolymer. ${ }^{2}$ Intra-BCN interactions are dominated by strong hydrogen bonds and attractive van der Waals forces, ${ }^{14}$ whilst inter$\mathrm{BCN}$ interactions are a combination of weaker hydrogen bonds and van der Waals forces..$^{15-17}$

Breaking down the hierarchical structure of $\mathrm{BC}$ fibres to individual $\mathrm{BCN}$ allows the high stiffness of the cellulose crystal to be exploited. ${ }^{8}$ The bonds within an individual BCN are extremely strong and are responsible for the high axial chain stiffness of $\mathrm{BC}^{4}$. The bonds between neighbouring $\mathrm{BCNs}$ are weaker. While the inter-BCN network is more disordered, it is still relatively robust, making it extremely difficult to dissolve. ${ }^{8} \mathrm{BC}$ fibres are insoluble in 
water and in common organic solvents. ${ }^{18}$ Despite this challenge, a number of methods to completely solubilise BC have been reported, many of which are reviewed by Lindman et al. ${ }^{18}$ Such routes include the use of lithium chloride/N,N-dimethylacetamide, ${ }^{19} \mathrm{NaOH} / \mathrm{urea}$ aqueous solution, ${ }^{20} \mathrm{ZnCl}_{2}$ aqueous solutions, ${ }^{21}$ ionic liquids, ${ }^{22}$ and $\mathrm{N}$-methyl morpholine-Noxide (NMMO) hydrate. ${ }^{23} \mathrm{BC}$ fibres can be reconstituted from these solutions using spinning techniques. ${ }^{24}$ Unfortunately, these manufactured fibres were found to have lower degree of crystallinity (compared with the starting material) and hence lower mechanical properties. The hierarchical structure of cellulose can also be broken-down by mechanical processes., ${ }^{2,8}$ In such cases, cellulose materials are run through a number of mechanical treatments multiple times to produce micro- or nanofibrils. The high shear associated with these processes is known to diminish the mechanical properties of the exfoliated cellulose by damaging the crystalline phases. It should be noted that this method is not commonly used for BC.

To disrupt the network structure of $\mathrm{BC}$ to produce individualised $\mathrm{BCN}$, we gained inspiration from work that has been carried out in recent years on the dispersion of similarly insoluble 1dimensional (1D) materials, such as single-walled carbon nanotubes (SWNTs), ${ }^{25,} 26$ and nanowires $(\mathrm{NWs}){ }^{27}$ Like $\mathrm{BC}$, the properties of these materials are limited by their tendency to aggregate (through van der Waals interactions). Due to their rigidity and other factors, these macromolecules have very limited solubility in organic solvents. Nevertheless, solvents capable of producing stable dispersions of individual SWNTs and NWs were uncovered. The central finding of that work was that the concentration of exfoliated nanomaterial could be maximised by choosing solvents whose surface energies matched the surface energy of the nanomaterial. This paper outlines how $\mathrm{BC}$ can also be dispersed to individualised $\mathrm{BCN}$ in a range of organic solvents. It proposes a thermodynamic framework to predict dispersants for BC (based on BC's similarity to other rigid 1D nanomaterials). Neat films prepared from dispersed $\mathrm{BCN}$ show a clear correlation between the degree of dispersion and the mechanical properties of the BC films.

\section{Experimental Section}

\section{Materials}

BC was kindly provided by $f z m b \mathrm{GmbH}$ (Forschungszentrum für Medizintechnik und Biotechnologie, Bad Langensalza, Germany). The following organic liquids, N-methyl-2pyrrolidone, ethylene glycol, dioxane, dichloromethane, ethanol amine, cyclohexyl- 
pyrrolidone, benzyl alcohol, N-dodecyl-pyrrolidone, cyclohexanone and toluene (all HPLC grade), were purchased from Sigma-Aldrich. Inverse gas chromatography (IGC) probe molecules (decane, nonane, octane, heptane, hexane, ethanol and 1-proponal) were purchased from Sigma-Aldrich (all HPLC grade). Helium and methane (IGC carrier gas and dead-time probe gas) were purchased from BOC (research grade).

\section{Methods}

Freeze-drying $B C$

The BC was supplied as wet pellicles containing 94 wt.\% water. The synthesis of BC pellicles used in this study is described in literature. ${ }^{11}$ The BC pellicles were cut into small pieces and blended in to water for 2 min using a laboratory blender (LB20EG, Christison Particle Technologies, Gateshead, UK) at a concentration of $4 \mathrm{~g} \mathrm{~L}^{-1}$. The suspension was then further homogenised (Polytron PT 10-35 GT, Kinematica, Lucerne, $\mathrm{CH}$ ) for $2 \mathrm{~min}$ to produce a uniform suspension of $\mathrm{BC}$ in water. This suspension was then flash frozen in a Petri dish by immersion in liquid nitrogen and subsequently freeze-dried (Heto PowerDry LL1500 Freeze Dryer, Thermo Scientific, UK). The residual water content of the freeze-dried BC was determined using dynamic vapour sorption (DVS-Advantage, Surface Measurement Systems Ltd, Alperton, UK). $30 \mathrm{mg}$ of freeze-dried BC was loaded into the chamber of DVS held at $0 \%$ relative humidity for $5 \mathrm{~h}$. During this period, the mass change of the sample was measured. The residual water content was obtained from the difference between the initial and final mass of the sample. The equilibrium water content post freeze-drying was $23 \pm 6$ $\mathrm{mg} \mathrm{g}^{-1}$ (mg of water per gram of $\left.\mathrm{BC}\right){ }^{28}$

\section{$B C$ dispersion and characterisation}

Aliquots $\left(20 \mathrm{~mL}\right.$ at concentrations of $\left.1 \mathrm{mg} \mathrm{mL}^{-1}\right)$ of $\mathrm{BC}$ were dispersed in organic liquids using an ultrasonic tip (Sonics vibra cell $750 \mathrm{~W}$ tapered tip at $20 \%$ amplitude for 30 min with ice cooling) and centrifuged for $30 \mathrm{~min}$ at $4000 \mathrm{rpm}$. Tapping-mode Atomic Force Microscopy (Brucker Multimode, silicon cantilever with radius of $10 \mathrm{~nm}$ ) was used to assess the dispersion quality for each aliquot. Samples were prepared by taking a small drop from each dispersion and drop-casting it on $\mathrm{SiO}_{2}$ substrate and drying in a vacuum oven at $80{ }^{\circ} \mathrm{C}$ for $24 \mathrm{~h}$. These conditions were chosen to minimise re-aggregation on drying. The diameters of $>150$ nanofibrils were measured for each AFM sample. 
The concentration of dispersed BC in each solvent was determined spectroscopically. UVvis-NIR absorbance spectra were recorded with a Cary 6000i, Aglient. The extinction coefficient of $\mathrm{BC}$ at $600 \mathrm{~nm}$ (there are no absorption peaks in the spectrum in this range) was determined by measuring the absorbance of a series of step-wise dilutions whose precise concentrations were known. A stock mixture was prepared by adding $10.0 \pm 0.3 \mathrm{mg}$ of $\mathrm{BC}$ to $50.00 \pm 0.01 \mathrm{~mL}$ of NMP, and sonicating as described above. This stock solution was precisely diluted by $50 \%$ a number of times using volumetric flasks. The concentration of BC in dispersed media was calculated using the Beer-Lambert law ( $\mathrm{A}=\varepsilon \mathrm{cL})$, relating the absorbance, A, of a species to its extinction coefficient, $\varepsilon$; concentration, $c$; and the pathlength of the sample cell, L.

\section{BC film preparation}

Neat BC films were prepared form a range of organic liquids (see table 1). For each, 2 aliquots of $20 \mathrm{mg}$ of $\mathrm{BC}$ in $87.5 \mathrm{~mL}$ of organic liquid was sonicated (750 W for $3 \mathrm{~h}$, pulsing 5 $\mathrm{s}$ on/off with stirring and ice-cooling). The dispersion was vacuum filtered onto a Nylon membrane (Whatman, $47 \mathrm{~mm}$ diameter and $45 \mu \mathrm{m}$ pore size). The films were dried in a vacuum oven at $60{ }^{\circ} \mathrm{C}$ for 2 days. The tensile properties of each film were recorded using a Zwick Roell Z005 (equipped with a $100 \mathrm{~N}$ load cell). The porosity of the films was calculated based on dimensional analysis and the mass of $\mathrm{BC}$ films using the equation; $P=1-\frac{\rho_{\text {film }}}{\rho_{B C}}$, where $Q_{\mathrm{BC}}=1500 \mathrm{~kg} \mathrm{~m}^{-3} \cdot{ }^{29}$ Two of the neat cellulose films were subjected to mild hot-pressing $\left(10 \mathrm{~min}, 80{ }^{\circ} \mathrm{C}, 50 \mathrm{kN}\right.$ ) (Rondol Technology, UK) to assess the effect of increasing film density on tensile properties.

\section{Inverse gas chromatography (IGC)}

The surface energy of BC was measured using inverse gas chromatography (IGC) (Surface Energy Analyser, Surface Measurements Systems Ltd, UK). $10 \mathrm{mg}$ of freeze-dried BC was packed into a glass column of $2 \mathrm{~mm}$ internal diameter. Silanised wool was used to plug both ends. Samples were pre-conditioned in helium at a flow rate of $20 \mathrm{~mL} \mathrm{~min}^{-1}$ for $2 \mathrm{~h}$ at $80{ }^{\circ} \mathrm{C}$. Alkane probes were used to measure the dispersive surface energy of the sample and specific probes were injected through the sample to measure specific interactions. A flowrate of 20 $\mathrm{mL} \min ^{-1}$ and a temperature $30^{\circ} \mathrm{C}$ were used for all IGC measurements. Retention times were measured using a flame ionisation detector (FID). 
Dispersive and specific surface energies were measured for a range of sample surface coverages (between $0.5 \%$ and 30\%). To determine the amount of probe required for each coverage, the specific surface area of BC was measured by 5-point BET measurements using $\mathrm{N}_{2}$ sorption (Nova Quantachrome 4200E). $100 \mathrm{mg}$ of freeze-dried $\mathrm{BC}$ was heated to $100{ }^{\circ} \mathrm{C}$ for $8 \mathrm{~h}$ under vacuum before sorption measurements were taken.

\section{Results and Discussion}

BC Dispersions.

To determine if the network structure of BC could be disrupted by sonication to yield $\mathrm{BCN}$, $\mathrm{N}$-methyl pyrrolidone (NMP) was studied dispersing phase due to its remarkable success at dispersing carbon nanotubes, ${ }^{30}$ graphene ${ }^{31}$ and transition metal dichalcogenides. ${ }^{32}$ In this work, the sonication of freeze-dried BC in NMP produced a clear, homogenous dispersion (see figure 1a). A comparable experiment of BC sonicated in chloroform had little dispersive effect; $\mathrm{BC}$ remained aggregated and two phases were clearly visible (figure 1b). To assess the state of the BCN in NMP dispersion, AFM was used. A representative image for this sample is shown in (figure 1c) which shows a large population (figure 1d) of BCNs with average heights of $10.7 \pm 0.5 \mathrm{~nm}$ (figure 1e) and lengths of several micrometres (figure 1c). Such measurements are consistent with the dimensions of BCNs previously reported. ${ }^{3}$ Our results suggest that the networked assembly of primary BC has been successfully disrupted. It is important to stress that these findings do not suggest that NMP dissolved BC molecules, as NMMO or ionic liquids do, ${ }^{4}$ forming a polymer solution. 


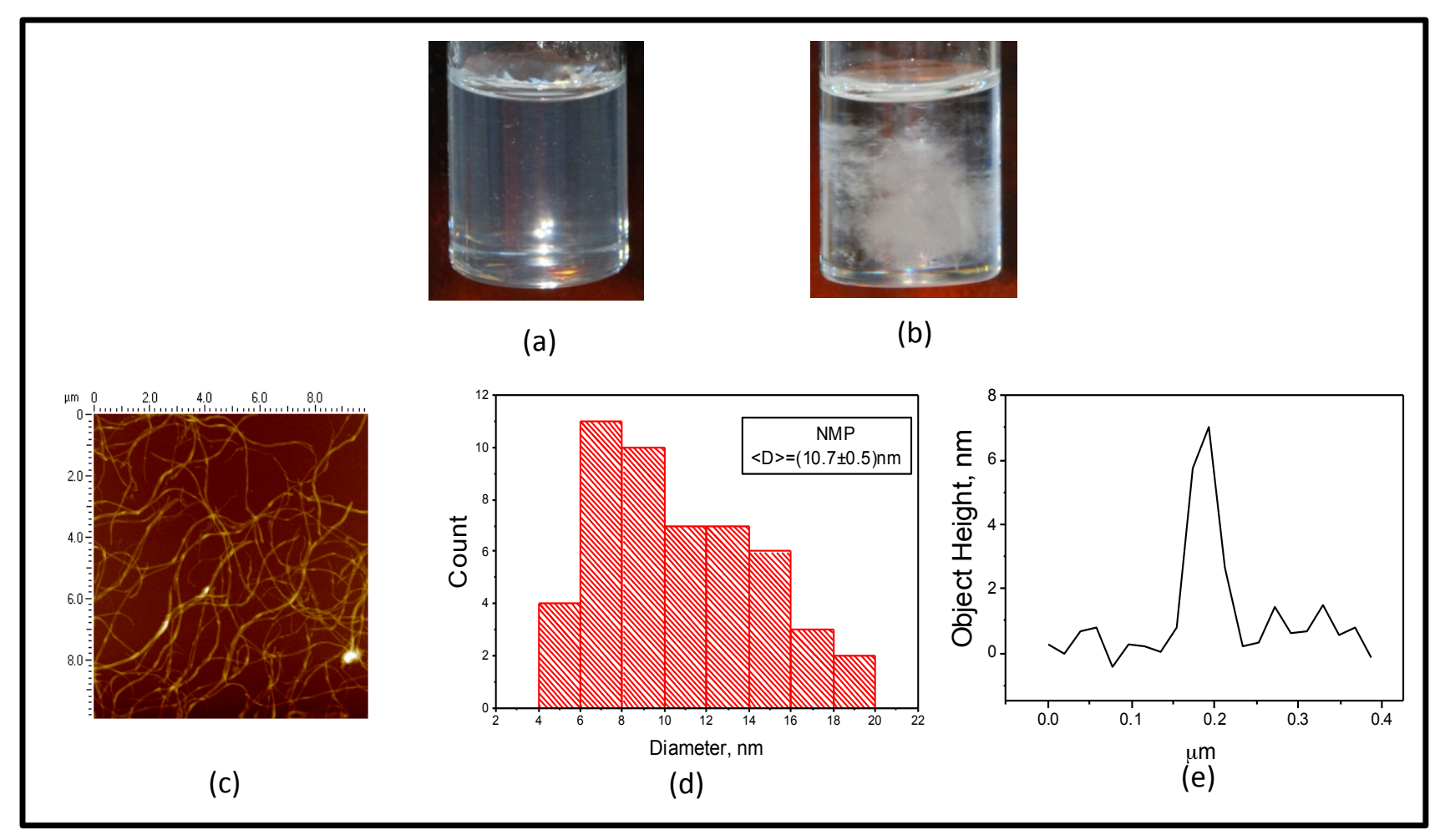

Figure 1: BC sonicated in (a) N-methyl-2-pyrrolidone (NMP) \& (b) chloroform. (c) AFM image of BCN-NMP dispersion. (d) AFM statistics of BCN-NMP dispersion. (e) Crosssection of a BCN marked as red line in (c).

The concentration of dispersed $\mathrm{BCN}$ in organic solvents was determined spectroscopically using the Beer-Lambert law $(\mathrm{A}=\varepsilon \mathrm{cL})$. A typical $\mathrm{BCN}$ absorption spectrum is shown in figure 2. The absorbance spectra of dispersed cellulose are dominated by a power-law scattering background at lower wavelengths $\left(\propto \lambda^{-n}\right)$. A scattering exponent, $n$, of $3.79 \pm 0.03$ was obtained from a fit of the spectrum in figure 2 . This exponent value is consistent with a Rayleigh scattering curve $\left(\propto \lambda^{-4}\right)$, where the dimensions of the scattering particles are small up to $\sim 10 \%$ of the wavelength of the incident light. The exponents of multiple spectra were recorded and were found to be independent of concentration. This consistency suggests differences in absorbance between spectra are due only to differences in concentration of dispersed BCN. 


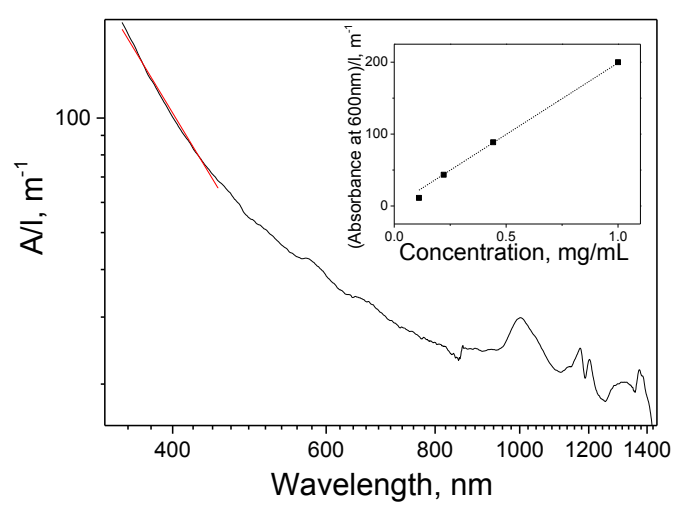

Figure 2: A typical UV-Vis spectrum of $\mathrm{BC}$. The dashed line is a fit of the scattering exponent $(\mathrm{n}=-3.79)$. The insert shows the absorbance at $600 \mathrm{~nm}$ of serially diluted $\mathrm{BC}$ dispersions. The dashed line is a fit of the data - the slope being the extinction

To apply the Beer-Lambert law and determine the concentration of dispersed BCN, it was necessary to first determine the extinction coefficient of BCN. Plotting the absorbance per unit length of a serially diluted BCN-NMP dispersion against concentration, as shown in the inset of figure 2, yielded an extinction coefficient of $200 \pm 22 \mathrm{~mL} \mathrm{mg}^{-1} \mathrm{~m}^{-1}$. To the best of our knowledge, there are no reported values of the extinction coefficient of BCN but this result is reasonably consistent with reported value of $264 \mathrm{~mL} \mathrm{mg}^{-1} \mathrm{~m}^{-1}$ for primary bacterial cellulose. ${ }^{33}$ Using our measured extinction coefficient, the concentration of dispersed BCN in NMP was determined to be $0.13 \pm 0.04 \mathrm{mg} \mathrm{mL}^{-1}$. To ensure that no BC sedimentation has occurred, the absorbance of the stock and serial dilutions was re-measured after 1 week; the change in absorbance was less than $5 \%$.

\section{Thermodynamic Prediction of Organic Solvents for BC Dispersions}

To investigate if other organic liquids enable dispersion of $\mathrm{BC}$ to elementary $\mathrm{BCN}$, samples were sonicated in a wide range of organic liquids (shown in SI table 1) in an analogous way to the NMP dispersion described above. Organic liquids producing poor dispersions, where two distinct phases (liquid and BC) were clearly evident after sonication, were discarded. The concentrations of dispersions of $\mathrm{BCN}$ in organic liquids that turned transparent upon sonication were determined spectroscopically and are shown in table 1. BC dispersions, with concentrations of up to $0.20 \mathrm{mg} \mathrm{mL}^{-1}$, were obtained in a range of organic liquids (table 1 ). 
To investigate the make-up of these dispersions, AFM measurements were conducted on samples prepared from the 10 solvent dispersions with the highest concentrations of dispersed BC. These images were analysed, measuring the heights of $\sim 150$ BC nanofibrils per dispersion, as shown in figure S2. Average object height measured for each solvent ranged from $10.7 \pm 0.5 \mathrm{~nm}$ NMP to $16.2 \pm 0.7 \mathrm{~nm}$ for cyclo-hexyl-pyrrolidone. These data suggest that a reasonable population of individual nanofibrils are present in all of the more successful organic liquids.

Table 1: Concentration of dispersed BCN in organic liquids

\begin{tabular}{|l|l|}
\hline Solvent & Concentration of BCN, $\mathbf{~ m g ~} \mathbf{~ L L}^{-1}$ \\
\hline N-ethyl-2-pyrrolidone & $0.20 \pm 0.11$ \\
\hline Dioxane & $0.16 \pm 0.09$ \\
\hline Dichloromethane & $0.16 \pm 0.04$ \\
\hline Ethanol amine & $0.16 \pm 0.03$ \\
\hline Cyclohexyl-pyrrolidone & $0.13 \pm 0.04$ \\
\hline N-methyl-pyrrolidone & $0.13 \pm 0.04$ \\
\hline Benzyl alcohol & $0.12 \pm 0.03$ \\
\hline N-dodecyl-pyrrolidone & $0.11 \pm 0.02$ \\
\hline Toluene & $0.11 \pm 0.01$ \\
\hline
\end{tabular}

In order to ascertain the qualities of a 'good dispersion medium' for $\mathrm{BC}$ and predict effective liquids to disperse $\mathrm{BC}$, we turn to the considerable body of work on the dispersion of single walled carbon nanotubes (SWNTs) as both can be considered to be rigid 1D systems with limited dispersibility in most common solvents. ${ }^{25}$ A good dispersion medium implies a thermodynamically stable mixture over a range of concentrations and temperatures ${ }^{34}$ (i.e. $\Delta G_{\text {mix }}$ is close to 0 or negative). Previous findings showed the challenge of dispersing rigid 1D rigid nanoparticles stems from the fact that the entropy of mixing, $\Delta S_{\text {mix }}$, is very small for dispersions of rigid 1D macromolecules. ${ }^{35}$ Thus, the enthalpy of mixing, $\Delta H_{\text {mix }}$, must be small or negative, for mixing to occur. $\Delta H_{\text {mix }}$ for mixtures of solvents and SWNTs was found to be minimised when the surface energy of the solvent, $\gamma_{1}$, matched that of the nanotubes, $\gamma_{\mathrm{NM}}{ }^{25}$

$\frac{\Delta H_{\text {mix }}}{V_{\text {mix }}} \approx \frac{2}{R_{\text {Bun }}}\left(\gamma_{N M}-\gamma_{l}\right)^{2}$ 
where $R_{\mathrm{Bun}}$ is the radius of the bundle of SWNTs and $\phi$ the SWNT volume fraction. The surface energy of a solvent is related to its surface tension, $\sigma$, using the equation: $\gamma=\sigma-\mathrm{TS}$, where $S$ is the universal value for surface entropy ${ }^{36}$ of $\sim 0.1 \mathrm{~mJ} \mathrm{~m}^{-2} \mathrm{~K}^{-1}$.

The route to discover a suitable dispersion medium for nanomaterials that aggregate through van der Waals forces, summarised in equation 1 , has been remarkably successful. ${ }^{25,37,38}$ Solubility studies for SWNTs, graphene, and a range of other 2D nanomaterials show a peak in concentration of the dispersed material in organic liquids with surface energies close to 70 $\mathrm{mJ} \mathrm{m}{ }^{-2}$, where the surface energies for each of these nanomaterials are reported as being close to $70 \mathrm{~mJ} \mathrm{~m}^{-2}$. Figure 2 shows the concentration of dispersed BCNs (in a range of solvents) plotted against the surface energy $\left(\gamma_{\text {dis }}\right)$ and surface tension $\left(\sigma_{\text {dis }}\right)$ of the dispersion medium. One can clearly see from figure 2 that optimum dispersion media have similar surface energies. Our findings suggest the physical properties of organic solvents used as dispersion medium of a range of low-dimensional nanomaterials, appear to also apply to the dispersion of $\mathrm{BC}$, a material in which aggregation is due to combination of van der Waals and $\mathrm{H}$ bonding forces. Equation 1 implies that since stable dispersions of $\mathrm{BCN}$ are produced in organic solvents with surface energies close to $75 \mathrm{~mJ} \mathrm{~m}^{-2}$, the surface energy of BC must be close to $75 \mathrm{~mJ} \mathrm{~m}^{-2}$. We note, however, that it is difficult to find suitable organic liquids to test BC dispersibility with higher surface energy values. Whilst the potential sonochemical degradation of solvents should be considered, particularly when designing assemblies for particular applications ${ }^{39}$, there is a clear trend with surface tension. Thus, an accurate measure of BC's surface energy is essential to ensure the dispersion route outlined in equation 1 is valid for $\mathrm{BC}$ and furthermore to demonstrate that this route toward liquid-phase exfoliation can be applied to systems that are not bound solely by van der Waals forces.

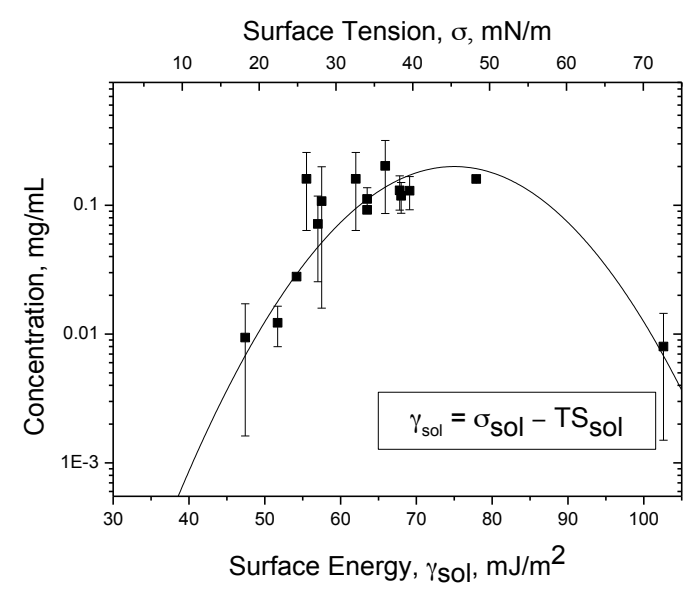


Figure 2: Concentration of BCN dispersed in various organic liquids plotted against liquid surface tension $(\sigma)$ and surface energy $(\gamma)$.

Inverse gas chromatography (IGC) was used to determine the surface energy of BC. Whilst numerous techniques have been reported to measure the surface tension of natural fibres, it seems that those based on the analysis of measured contact angles are unsuited to the natural fibres with an irregular geometry. ${ }^{40}$ Using IGC, the surface energy of a packed bed of freezedried $\mathrm{BC}$ is determined from measured retention times, $\mathrm{t}_{\mathrm{n}}$, (and corresponding retention volumes, $\mathrm{V}_{\mathrm{n}}$ ) for a series of known probe molecules eluting through a column packed with the target material (in this case, BC). A series of n-alkane probes was used to determine the dispersive component of BC's surface energy, $\gamma_{\mathrm{D}}$, using a model introduced by Schultz et al.:.$^{41}$

$$
\Delta G=R T \ln V_{N}=2 N_{a}\left(\gamma_{d}\right)^{\frac{1}{2}} a\left(\gamma_{d, l}\right)^{\frac{1}{2}}+C
$$

where $\Delta \mathrm{G}$ is the Gibbs free energy of adsorption, $\mathrm{T}$ the column temperature, $\mathrm{R}$ the gas constant, $\mathrm{N}_{\mathrm{A}}$ Avogadro's number, $\gamma_{\mathrm{D}, 1}$ the dispersive free surface energy of the adsorbate (the probe) in the liquid phase, $a$ the molecular cross-section of the adsorbate, and $\mathrm{C}$ a constant. Thus, $\gamma_{D}$ can be determined from a plot of $R T \ln V_{n} v s$. $a\left(\gamma_{D, 1}\right)^{1 / 2}$. Figure $3 a$ shows data recorded by IGC where probe molecules covered $6 \%$ of the $\mathrm{BC}$ surface. The dashed line is a fit to these data, which corresponds to a $\gamma_{\mathrm{D}}$ value of $42.3 \mathrm{~mJ} / \mathrm{m}^{2}$. 


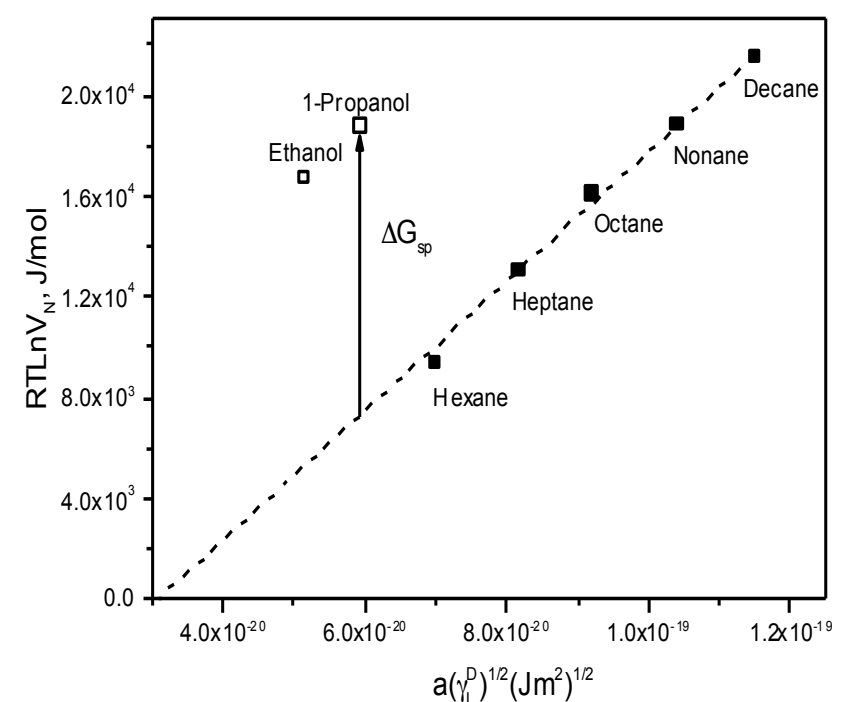

(a)

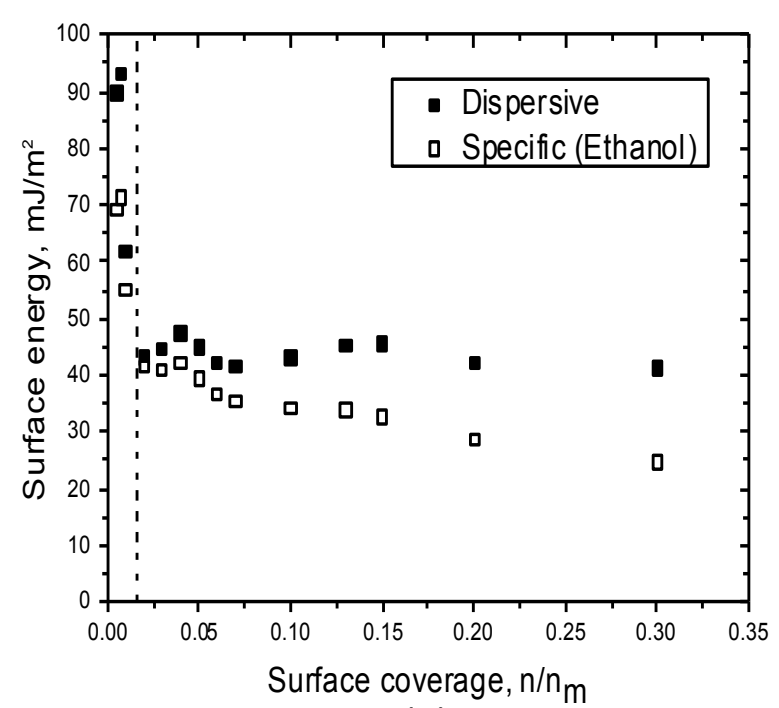

(b)

Figure 3: (a) Free-energy of adsorption $\left(R T \ln V_{N}\right)$ as a function of dispersive energy of IGC probe vapour $\left(\gamma_{L}^{D}\right)$ and the probes cross-sectional area (a). These data correspond to $6 \%$ BC surface-coverage. A series of n-alkanes is shown by the solid squares and specific probe molecules are represented by open squares. The dotted line is a fit of the n-alkane data used to determine the dispersive surface energy of the solid sample (as shown by equation 2). (b) Dispersive and specific surface energy (ethanol used as probe solvent) of $\mathrm{BC}$ as a function of $\mathrm{BC}$ surface-coverage. Data to the right of the dashed line results from n-alkane fits where $R^{2}>0.99$.

As outlined previously, BCNs aggregate through a combination of van der Waals and $\mathrm{H}$ bonding forces. ${ }^{42}$ Thus, the total surface energy of $\mathrm{BC}$ will reflect the energies required to disrupt both van der Waals interactions and other specific interactions. The dispersive component of surface energy, $\gamma_{\mathrm{D}}$, of BC determined by IGC accounts for van der Waals interactions and does not incorporate the contribution of specific interactions, such as $\mathrm{H}$ bonds, to BC's surface energy. To measure the total surface energy of any material we can crudely sum the dispersive term, $\gamma_{\mathrm{D}}$, and the specific terms, $\gamma_{\mathrm{sp}}{ }^{43} \gamma_{\mathrm{sp}}$ can be determined using IGC, as $\Delta \mathrm{G}_{\mathrm{sp}}$ using: 


$$
\Delta G_{s p}=R T \ln V_{n}-R T \ln V_{n}^{r e f}
$$

i.e. the difference of $R T \ln V_{n}$ for the specific probe and the corresponding dispersive reference line (as shown in figure 3a). The value for $\Delta \mathrm{G}_{\mathrm{sp}}$ is given in $\mathrm{kJ} / \mathrm{mol}$, which can be converted to $\mathrm{mJ} / \mathrm{m}^{2}$ using ${ }^{44}$ :

$$
\gamma_{s p}=\frac{\Delta G_{s p}}{a N_{A}}
$$

Measured values of $\gamma_{\mathrm{sp}}$ are not intrinsic to the solid as they rely on interaction between the probe and the solid surface. They do, however, give an excellent indication of the solid's specific surface energy. Specific surface energies were measured for a number of probe molecules: $\gamma_{\mathrm{sp}}($ ethanol $)=36.5 \mathrm{~mJ} / \mathrm{m}^{2}$ and $\gamma_{\mathrm{sp}}(1$-propanol $)=30.1 \mathrm{~mJ} / \mathrm{m}^{2}$. One can sum $\gamma_{\mathrm{D}}$ and $\gamma_{\mathrm{sp}}$ terms to give a rather crude figure for the total solid surface energy ${ }^{45}$. Depending on the specific probe, the total surface energy for BC ranges from $\sim 72-79 \mathrm{~mJ} / \mathrm{m}^{2}$.

In general, published values of dispersive surface energy cellulose (as measured with IGC) are higher than those presented in this work. Papirer et al. ${ }^{46}$ report $\gamma_{\mathrm{D}}$ values up to $52.3 \mathrm{~mJ} / \mathrm{m}^{2}$ for microcrystalline cellulose and claimed dispersive and specific surface energies of cellulose scale with the degree of cellulose crystallinity. These authors also showed specific probes capable of $\mathrm{H}$-bonding with cellulose to yield higher specific surface energy values $\left(\gamma_{\mathrm{sp}}=78.6 \mathrm{~mJ} / \mathrm{m}^{2}\right.$ for ethanol $\left.(16.7 \mathrm{~kJ} / \mathrm{mol})\right)$ than other specific probes that are not capable of such H-bonding. Elsewhere, $\gamma_{\mathrm{D}}$ values for BC of $61.0 \mathrm{~mJ} \mathrm{~m}{ }^{-2(40)}$ and $65.4 \mathrm{~mJ} / \mathrm{m}^{2(47)}$ have been reported. These values are higher than those for other forms of cellulose, a result attributed to the effects of crystallinity. ${ }^{48}$ It is worth noting that for these studies, IGC measurements were made at infinite dilution, where solvent molecules preferentially probe high-energy sites leading to high values of surface energies. In the current work, we intended to measure the surface energy of $\mathrm{BC}$ as seen by solvating molecules and, therefore, need to measure surface energy at finite dilution (higher surface coverage). Edge sites and defects will have different energies than 'bulk' surface sites. IGC allows the measurement of a surface energy profile of a heterogeneous solid sample by injecting precise amounts of probe molecules to yield a certain surface coverage of the sample. Nanomaterials often have a higher degree of heterogeneity, as edge and vertex sites represent a greater fraction of the total surface area. To investigate how surface energy (both $\gamma_{\mathrm{D}}$ and $\gamma_{\mathrm{sp}}$ ) of BC depends on the degree of samplecoverage the probe molecule achieves, IGC measurements were made for a range of surface 
coverages. Figure $3 \mathrm{~b}$ shows $\gamma_{\mathrm{D}}$ and $\gamma_{\mathrm{sp}}$ values fall sharply as adsorbate surface-coverage increases and then reach a plateau. Measured values of $\gamma_{\mathrm{D}}$ and $\gamma_{\mathrm{sp}}$ at low surface coverages are consistent with values for BC referenced above. The surface energy in the plateau region is a far more informative figure for dispersibility studies, where interaction with a liquid will be across most, if not all of the surface ${ }^{49}$. Assuming that the plateau value from figure $3 \mathrm{~b}$ of $79 \pm$ $7 \mathrm{~mJ} \mathrm{~m}^{-2}$, can be extrapolated to the fully solvated situation, ${ }^{49}$ there appears to be good agreement with the dispersibility study shown in figure 2, which suggested that solvents with surface energies of $\sim 75 \mathrm{~mJ} / \mathrm{m}^{2}$ were best for dispersing BC. The broad overlap of BC surface energy values (as measured by IGC) with the surface energies of solvents that yielded stable $\mathrm{BC}$ dispersions (as shown in figure 2) suggests that the approach of matching the surface energy of the dispersion medium to that of $\mathrm{BC}$, to disperse $\mathrm{BC}$ to their constituent $\mathrm{BCN}$, is valid. Whilst not every organic liquid that fulfils this criterion will produce BCN dispersions, the method is an excellent aid for identifying new dispersion media.

\section{Neat Cellulose Films}

In order to ascertain the effect of $\mathrm{BCN}$ dispersant choice on the mechanical properties of processed material, BC was dispersed in a range of organic liquids (and water) and processed to form pure BCN films (nanopapers) by vacuum filtration against a Nylon membrane. Wellformed, free-standing BCN films (approx. $1.5 \mathrm{mg}$ in mass) were obtained (typical photograph shown in figure $4 a$ ), with a porous nanofibrous architecture clearly visible via helium ion microscopy (figure 4b). Based on envelope density, the films were found to have a porosity in range of 40-70\%, directly after vacuum drying (table 2). The tensile properties of the BCN films are shown in figure 5a (and table S2). Tensile strengths and moduli of films with a porosity of around $40 \%$ reached up to $114 \pm 12 \mathrm{MPa}$ and $2.2 \pm 0.7 \mathrm{GPa}$, respectively. These values are lower than those reported elsewhere for films hot compacted against a hydrophobic surface during drying (which prevents the film from shrinking). Considering the low-density/high-porosity nature of the films reported herein, however, the mechanical properties are within the range of mechanical responses for cellulose films, as reviewed by Moon et al. ${ }^{2}$ 


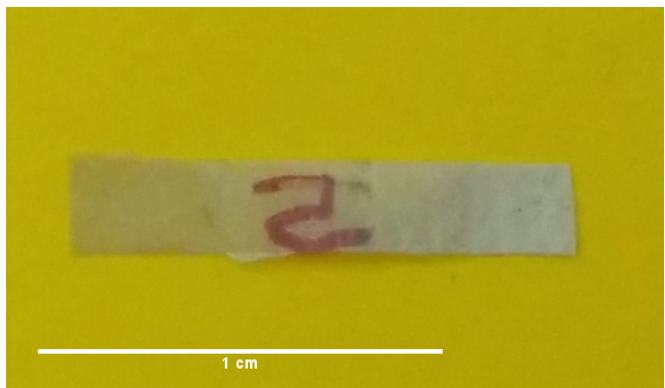

(a)

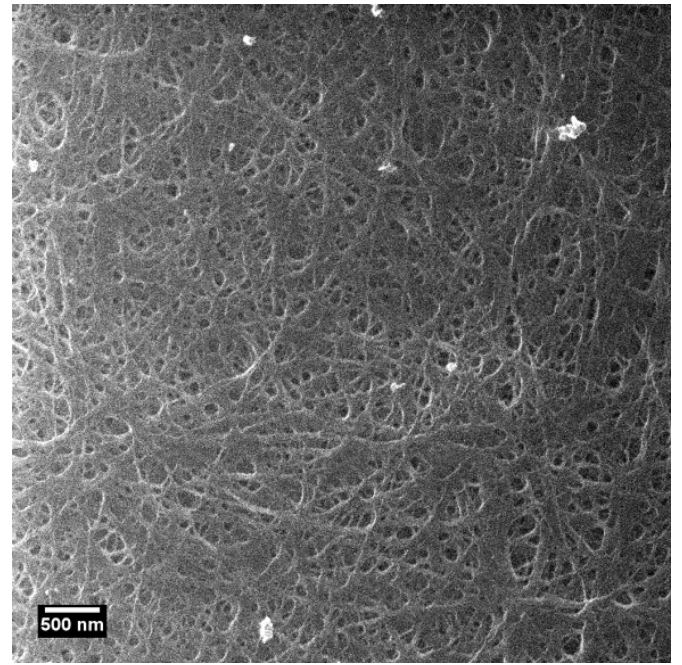

(b)

Figure 4: (a) Photography of a typical BCN film and (b) Helium ion image of $\mathrm{BCN}$ porous network; both prepared using NMP as the solvent.

Table 2: Density and porosity of $\mathrm{BCN}$ films. Mechanical response of these films is shown in figure 5.

\begin{tabular}{|c|c|c|c|}
\hline liquid & $\mathbf{N}$ & $\begin{array}{c}\boldsymbol{\rho}_{\text {film }} \\
\left(\mathbf{k g} / \mathbf{m}^{3}\right)\end{array}$ & $\begin{array}{c}\text { Porosity, \% } \\
\text { (P) }\end{array}$ \\
\hline $\begin{array}{c}\text { N-Methyl-pyrrolidone (hot } \\
\text { pressed) }\end{array}$ & 8 & $1084 \pm 113$ & $28 \pm 3$ \\
\hline Ethanol amine & 7 & $929 \pm 48$ & $38 \pm 2$ \\
\hline N-Methyl-pyrrolidone & 7 & $909 \pm 87$ & $39 \pm 4$ \\
\hline Cyclohexanone (hot pressed) & 9 & $836 \pm 102$ & $44 \pm 5$ \\
\hline Ethylene Glycol & 7 & $831 \pm 74$ & $45 \pm 4$ \\
\hline Dimethyl-formamide & 7 & $810 \pm 36$ & $46 \pm 2$ \\
\hline Dioxane & 7 & $570 \pm 52$ & $62 \pm 6$ \\
\hline Cyclohexanone & 7 & $462 \pm 100$ & $69 \pm 15$ \\
\hline Water & 9 & $852 \pm 152$ & $43 \pm 8$ \\
\hline
\end{tabular}




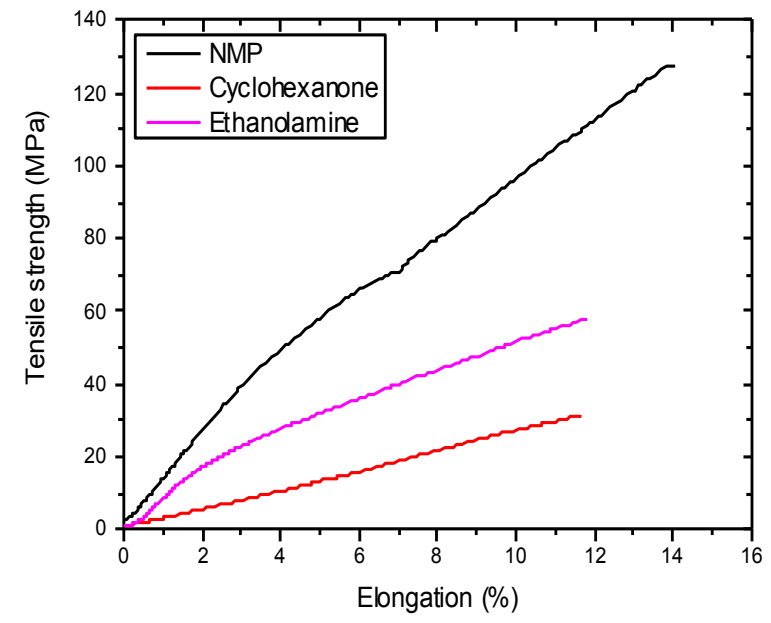

(a)

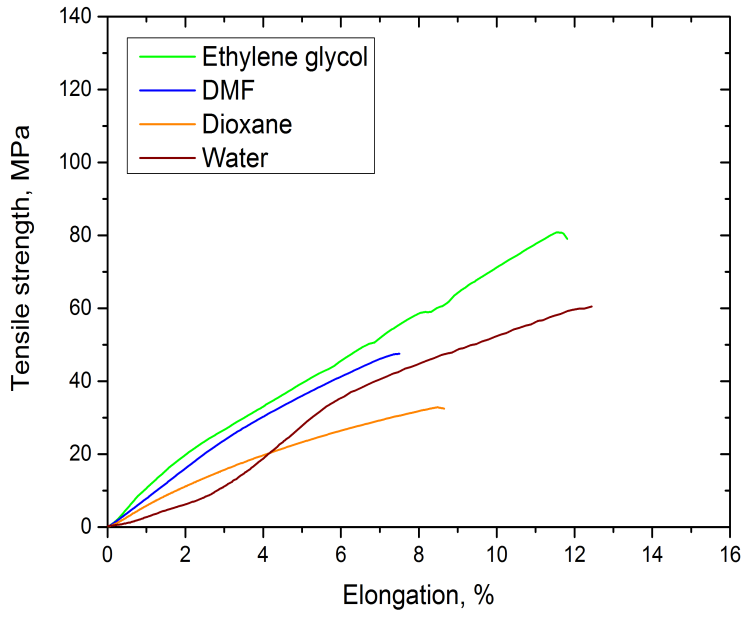

(b)

Figure 5: (a) Representative stress-strain curves of individual $\mathrm{BCN}$ films prepared by N-Methyl-pyrrolidone (NMP) (black), cyclohexanone (red) and ethanolamine (magenta). (b) Representative stress-strain curves of individual BC papers prepared by ethylene glycol (green), Dimethyl-formamide (DMF) (blue), dioxane (orange) and water (wine).

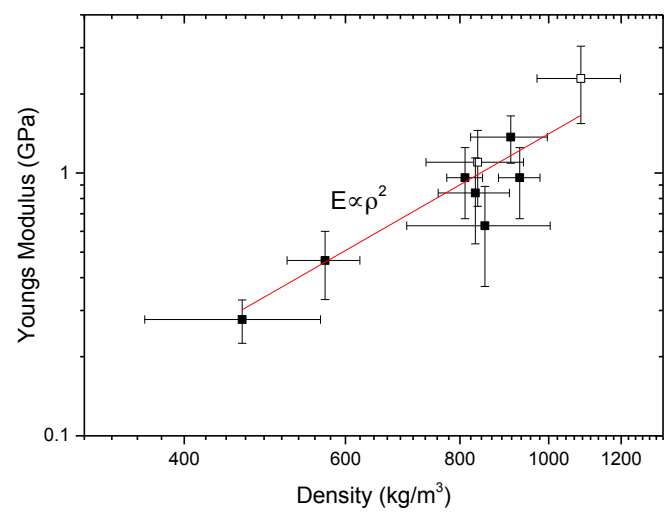

Figure 6: Young's modulus of BCN films prepared in a variety of solvents as a function of paper density. The function Young's modulus $\propto \varrho^{2}$ is fitted to the data. The clear data points correspond to $\mathrm{BC}$ papers that have been hot pressed. 
Several factors have been shown elsewhere to affect the mechanical response of pure cellulose films, including orientation of the constituent fibrils, ${ }^{50}$ porosity, ${ }^{51}$ the density of contact-points between fibrils, ${ }^{52-54}$ the fibril morphology and moisture content. ${ }^{2}$ This breadth of factors gives one excellent opportunity to engineer films as required for further applications.

In the current experiments, the Young's moduli of the films scale with the square of the BC paper density (figure 6). Such a square-dependence is consistent with a well-ordered hierarchical structure as opposed to the $\mathrm{E} \propto \mathrm{Q}^{3}$ trend observed for more disordered structures. ${ }^{55}$ Recent work by Qui et al. ${ }^{56}$ on low-density graphene structures also observed a densitysquared relationship with Young's modulus. If we consider BCN films to be random planar networks of rigid fibres, where exfoliation of the constituent fibrils is essential to their overall mechanical performance, we can draw analogies with the considerable body of work published for single-walled carbon nanotube (SWNTs) films. The mechanical behaviour of SWNT films was correlated with the SWNT-SWNT junction-density by Blighe et al. ${ }^{57}$ accounting for the fact that mechanical properties of these films are most likely controlled by a combination of nanomaterial size and porosity. Whilst the constituent SWNTs are extremely strong, the mechanical properties of a film made from them will be limited by the properties of the weakest links, the junctions of criss-crossing nanotubes. The number of junctions per volume, $\mathrm{N}_{\mathrm{J}}$, was given by:

$$
N_{J} \approx \frac{16}{3 \pi} \frac{(1-P)^{2}}{D^{3}}
$$

where $\mathrm{P}$ is the porosity of the film and $\mathrm{D}$ the average diameter of the nanomaterial. The tensile strength, Young's modulus, and toughness of SWNT films were shown to scale linearly with $(1-P)^{2} / D^{3}$. One might expect that films of neat BCNs should show a similar dependence if nanofibril junction density controls their overall mechanical response. To test this hypothesis, the mechanical response of $\mathrm{BCN}$ films was plotted against the number of junctions per volume, $\mathrm{N}_{\mathrm{J}}$, for each paper. AFM was used to measure the average bundle diameter of the $\mathrm{BC}$ nanofibrils (with statistics shown in figure S2). Figure 7a shows that Young's modulus of BCN films indeed scales with $\mathrm{N}_{\mathrm{J}}$. Whilst it has been demonstrated that the Young's modulus of low-density films scales with the film density, this work shows that reducing the average diameter of the constituent $\mathrm{BCN}$ fibres dramatically improves the modulus of the film, by increasing the density fibril/fibril junctions. 
The tensile strength of the BCN films also scaled with $\mathrm{N}_{\mathrm{J}}$ (Figure $7 \mathrm{~b}$ ). Blighe et al. ${ }^{57}$ also demonstrated that the average force required to break a junction in a SWNT film, $\mathrm{f}_{\mathrm{J}}$, could be determined from a fit of tensile strength, $\sigma$, against $\mathrm{N}_{\mathrm{J}}$. Speculating that any film fracture involves the breaking of junctions in a volume, $\mathrm{V}_{\mathrm{R}} \sim \mathrm{AL}$, where $\mathrm{A}$ is the film cross-sectional area and $\mathrm{L}$ the mean fibre length and that, on fracture, every bundle in this volume breaks half its junctions, gave the film strength as:

$$
\sigma \sim \frac{f_{J} L}{2} N_{J}
$$

Fitting this equation to the data in $7 b$ gives $f_{J} \sim(366 \pm 90) p N$, where $L$ was measured from AFM images of the dispersed BCN material (in NMP), $\langle\mathrm{L}>=(1.35 \pm 0.40) \mu \mathrm{m}$. This value of $\mathrm{f}_{\mathrm{J}}$ for the BCN film compares with that of $\mathrm{f}_{\mathrm{J}} \sim 113 \mathrm{pN}$ for a film of SWNTs. The higher value of $f_{J}$ for the $B C N$ film is not surprising when one considers the combined effects of $\mathrm{H}$ bonding and van der Waals forces between BCNs. If we consider a junction of 2 bundles with an overlap area of $100 \mathrm{~nm}^{2}$, then the energy required to separate the 2 nanofibrils to a distance of $100 \mathrm{~nm}$ is $\sim 3.66 \times 10^{-17} \mathrm{~J}$, corresponding to a surface energy of $\sim 183 \mathrm{~mJ} / \mathrm{m}^{2}$. Inverse gas chromatography data suggests the surface energy of bacterial cellulose is $\sim 79 \mathrm{~mJ}$ $\mathrm{m}^{-2}$. One might expect the calculated value of the surface energy (from $\mathrm{f}_{\mathrm{J}}$ ) to be an overestimate as it assumes perfect contact between two BCNs in a junction. Considering the very approximate nature this calculation, these two figures for BCN surface energy show surprisingly good agreement.

The relationship shown in figures $7 \mathrm{a}, \mathrm{b}$ between the mechanical response of neat BCN films and the bundle number density, $\mathrm{N}_{\mathrm{J}}$, of the film, suggests that one can control the mechanical properties of a film by carefully controlling the extent of $\mathrm{BCN}$ dispersion from which the films/nanopapers are being produced. Moon et al.'s extensive review ${ }^{2}$ on cellulose nanomaterials shows the mechanical properties of neat BCN films to be strongly influenced by issues including pellicle purification, compaction pressure, drying temperature, and pellicle defibrillation. This paper adds to that work showing the extent of $\mathrm{BCN}$ exfoliation (as given by the bundle junction density) to have significant impact on the film's mechanical behaviour. 
(a)

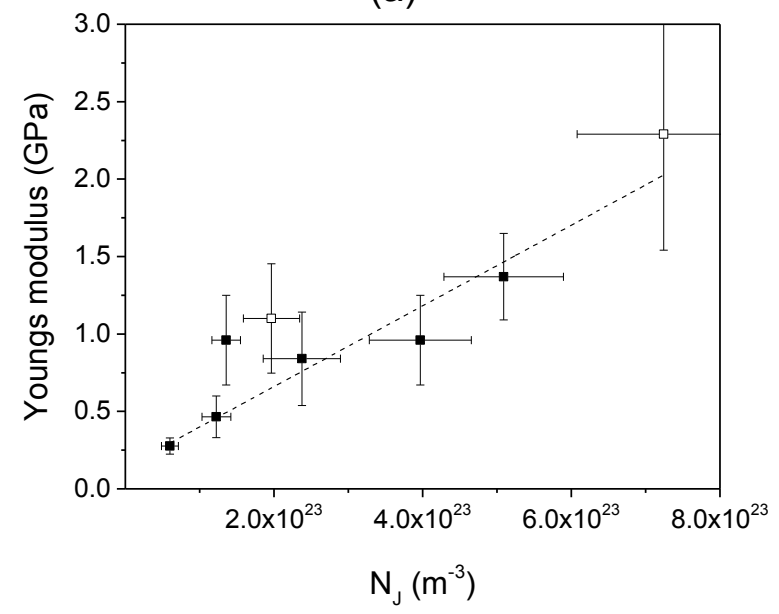

(c)

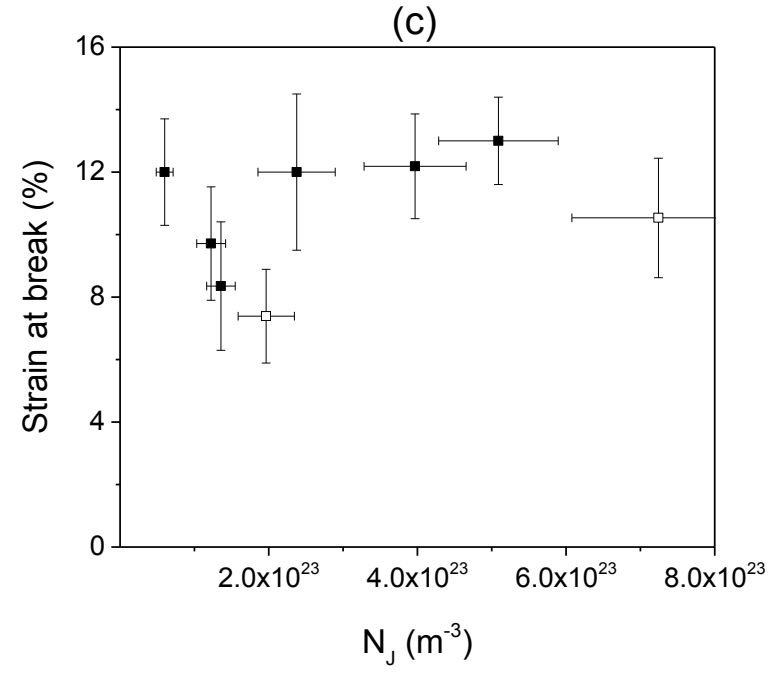

(b)

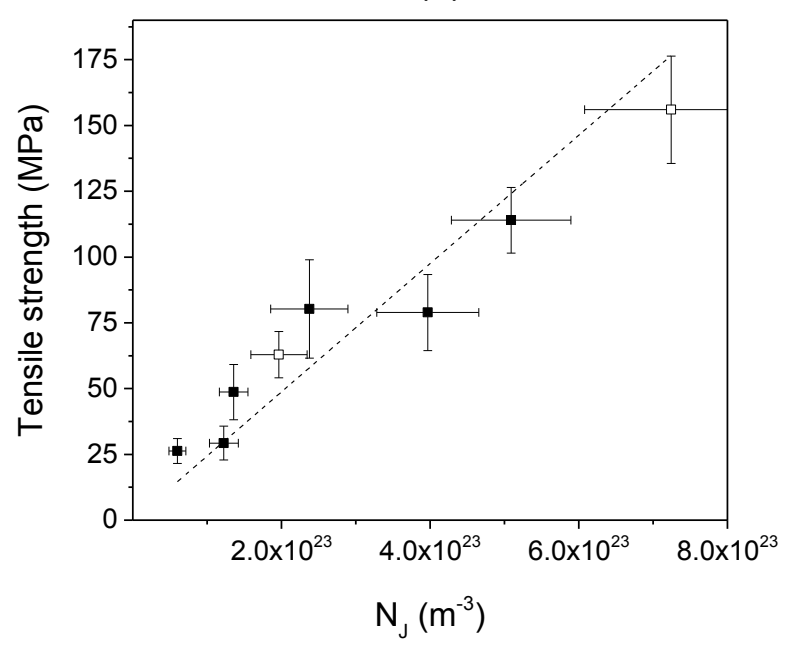

Figure 7: (a) Young's modulus, E (b) Tensile strength, $\sigma$, and (c) strain-at-break, $\varepsilon_{\mathrm{B}}$, plotted against the $\mathrm{BCN}$ junction density of $\mathrm{BCN}$ films. The dotted lines in (a) and (b) are fits of the data. The clear squares correspond to films that have been hot-pressed. 


\section{Conclusion}

In this work, bacterial cellulose was exfoliated from its primary fibres to its constituent nanofibrils (BCNs) by liquid phase exfoliation. The highest concentrations of dispersed BCN were found for liquids whose surface energies matched the surface energy of BC (as measured by inverse gas chromatography). In this regard, the dispersibility of BC appears to follow a similar trend to the dispersiblity of other low dimensional nanomaterials such as graphene and single-walled carbon nanotubes. Whilst the predictive power of this route to exfoliated $\mathrm{BCN}$ is not absolute, it is a guide to uncovering new dispersion media for this intractable material. Notably, the ability of IGC to measure heterogeneity plots, and hence indicate the likely surface energy at realistic coverage, is an important advance in the current context and many others.

Pure films of BCN produced from dispersions, in various solvents, showed a strong correlation between the mechanical response of the film and the degree of $\mathrm{BCN}$ exfoliation (expressed as a BCN bundle junction-density). Our findings suggest a novel means to control the mechanical properties of BCN films, by considering and optimising the junctions within the films. In the same way that the approach has been inspired by work on SWNTs, similar arguments and strategies are likely to apply to other nanomaterial systems. 


\section{ASSOCIATED CONTENT}

\section{Supporting information}

- Table S1. The complete range of solvents used in the bacterial cellulose solubility study.

- Figure s1. Height (diameter) of BC nano-fibrils from optimal solvents measured from AFM

- Table s2. Porosity and mechanical information of BC films made using a range of solvents

This material is available free of charge via the Internet at http://pubs.acs.org.

\section{Author Contributions}

The manuscript was written through contributions of all authors. All authors have given approval to the final version of the manuscript. $¥$ These authors contributed equally. (match statement to author names with a symbol)

\section{Funding Sources}

Science Foundation Ireland's SIRG, Marie Curie Intra-European Fellowship programme.

\section{Notes}

Any additional relevant notes should be placed here.

\section{ACKNOWLEDGMENT}

The authors wish to acknowledge that funding for this work was provided by Science Foundation Ireland's SIRG scheme and the Marie Curie Intra-European Fellowship programme. 


\section{ABBREVIATIONS}

$\mathrm{BC}$, bacterial cellulose; IGC, inverse gas chromatography; AFM, atomic force microscopy; NMP, N-methyl-2-pyrrolidone; SWNT, single wall nanotube.

\section{References}

1. Iguchi, M.; Yamanaka, S.; Budhiono, A., Bacterial cellulose-a masterpiece of nature's arts. Journal of Materials Science 2000, 35, (2), 261-270.

2. Moon, R. J.; Martini, A.; Nairn, J.; Simonsen, J.; Youngblood, J., Cellulose nanomaterials review: structure, properties and nanocomposites. Chemical Society Reviews 2011, 40, (7), 3941-3994.

3. Tokoh, C.; Takabe, K.; Fujita, M.; Saiki, H., Cellulose Synthesized by Acetobacter Xylinum in the Presence of Acetyl Glucomannan. Cellulose 1998, 5, (4), 249-261.

4. Eichhorn, S. J.; Davies, G. R., Modelling the crystalline deformation of native and regenerated cellulose. Cellulose 2006, 13, (3), 291-307.

5. Guhados, G.; Wan, W.; Hutter, J. L., Measurement of the Elastic Modulus of Single Bacterial Cellulose Fibers Using Atomic Force Microscopy. Langmuir 2005, 21, (14), 66426646.

6. Hsieh, Y. C.; Yano, H.; Nogi, M.; Eichhorn, S. J., An estimation of the Young's modulus of bacterial cellulose filaments. Cellulose 2008, 15, (4), 507-513.

7. Matsuo, M.; Harashina, Y.; Ogita, T., Effects of Molecular Orientation and Crystallinity on Measurement by X-Ray Diffraction of the Crystal Lattice Modulus of Poly(vinyl alcohol) Prepared by Gelation/Crystallization from Solution. Polym J 1993, 25, (4), 319-328.

8. Eichhorn, S. J.; Dufresne, A.; Aranguren, M.; Marcovich, N. E.; Capadona, J. R.; Rowan, S. J.; Weder, C.; Thielemans, W.; Roman, M.; Renneckar, S.; Gindl, W.; Veigel, S.; Keckes, J.; Yano, H.; Abe, K.; Nogi, M.; Nakagaito, A. N.; Mangalam, A.; Simonsen, J.; Benight, A. S.; Bismarck, A.; Berglund, L. A.; Peijs, T., Review: current international research into cellulose nanofibres and nanocomposites. Journal of Materials Science 2010, $45,(1), 1-33$.

9. Mautner, A.; Lee, K.-Y.; Lahtinen, P.; Hakalahti, M.; Tammelin, T.; Lie, K.; Bismarck, A., Nanopapers for organic solvent nanofiltration. Chem. Commun 2014, 50, 57785781.

10. Lee, K.-Y.; Buldum, G.; Mantalaris, A.; Bismarc, A., More Than Meets the Eye in Bacterial Cellulose: Biosynthesis, Bioprocessing, and Applications in Advanced Fiber Composite. Macromol. Biosci 2013, 14, (1), 10-32.

11. Schlufter, K.; Schmauder, H.-P.; Dorn, S.; Heinze, T., Efficient Homogeneous Chemical Modification of Bacterial Cellulose in the Ionic Liquid 1-N-Butyl-3methylimidazolium Chloride. Macromolecular Rapid Communications 2006, 27, (19), 16701676.

12. Gama, M.; Gatenholm, P.; Klemm, D., Bacterial nanocellulose: a sophisticated multifunctional material. CRC Press: 2012.

13. P Ross; R Mayer; Benziman, M., Cellulose biosynthesis and function in bacteria. Microbiol. Mol. Biol. Rev 1991, 55, (1), 35-58.

14. Parthasarathi, R.; Bellesia, G.; Chundawat, S. P. S.; Dale, B. E.; Langan, P.; Gnanakaran, S., Insights into Hydrogen Bonding and Stacking Interactions in Cellulose. The Journal of Physical Chemistry A 2011, 115, (49), 14191-14202. 
15. Nishiyama, Y.; Johnson, G. P.; French, A. D.; Forsyth, V. T.; Langan, P., Neutron Crystallography, Molecular Dynamics, and Quantum Mechanics Studies of the Nature of Hydrogen Bonding in Cellulose I $\beta$. Biomacromolecules 2008, 9, (11), 3133-3140.

16. Cousins, S. K.; Brown Jr, R. M., Cellulose I microfibril assembly: computational molecular mechanics energy analysis favours bonding by van der Waals forces as the initial step in crystallization. Polymer 1995, 36, (20), 3885-3888.

17. Nishiyama, Y.; Sugiyama, J.; Chanzy, H.; Langan, P., Crystal Structure and Hydrogen Bonding System in Cellulose I $\alpha$ from Synchrotron X-ray and Neutron Fiber Diffraction. Journal of the American Chemical Society 2003, 125, (47), 14300-14306.

18. Lindman, B.; Karlström, G.; Stigsson, L., On the mechanism of dissolution of cellulose. Journal of Molecular Liquids 2010, 156, (1), 76-81.

19. Chen, P.; Kim, H. S.; Kwon, S. M.; Yun, Y. S.; Jin, H. J., Regenerated bacterial cellulose/multi-walled carbon nanotubes composite fibers prepared by wet-spinning. Current Applied Physics 2009, 9, (2 SUPPL.), e96-e99.

20. Phisalaphong, M.; Suwanmajo, T.; Sangtherapitikul, P., Novel nanoporous membranes from regenerated bacterial cellulose. Journal of Applied Polymer Science 2008, 107, (1), 292-299.

21. Lu, X.; Shen, X., Solubility of bacteria cellulose in zinc chloride aqueous solutions. Carbohydrate Polymers 2011, 86, (1), 239-244.

22. Fischer, S.; Leipner, H.; Thümmler, K.; Brendler, E.; Peters, J., Inorganic molten salts as solvents for cellulose. Cellulose 2003, 10, (3), 227-236.

23. Fink, H. P.; Weigel, P.; Purz, H. J.; Ganster, J., Structure formation of regenerated cellulose materials from NMMO-solutions. Progress in Polymer Science 2001, 26, (9), 14731524.

24. Gao, Q.; Shen, X.; Lu, X., Regenerated bacterial cellulose fibers prepared by the NMMO·H2O process. Carbohydrate Polymers 2011, 83, (3), 1253-1256.

25. Bergin, S. D.; Nicolosi, V.; Streich, P. V.; Giordani, S.; Sun, Z.; Windle, A. H.; Ryan, P.; Niraj, N. P. P.; Zhi-Tao; Wang, T.; Carpenter, L.; Blau, W. J.; Boland, J. J.; Hamilton, J. P.; Coleman, J. N., Towards Solutions of Single-Walled Carbon Nanotubes in Common Solvents. Advanced Materials 2008, 20, (10), 1876-1881.

26. Coleman, J. N., Liquid-Phase Exfoliation of Nanotubes and Graphene. Advanced Functional Materials 2009, 19, (23), 3680-3695.

27. Nicolosi, V.; Vrbanic, D.; Mrzel, A.; McCauley, J.; O'Flaherty, S.; McGuinness, C.; Compagnini, G.; Mihailovic, D.; Blau, W. J.; Coleman, J. N., Solubility of Mo6S4.5I4.5 Nanowires in Common Solvents: A Sedimentation Study. The Journal of Physical Chemistry B 2005, 109, (15), 7124-7133.

28. Lee, K.-Y.; Bismarck, A., Susceptibility of never-dried and freeze-dried bacterial cellulose towards esterification with organic acid. Cellulose 2012, 19, (3), 891-900.

29. Lee, K.-Y.; Tammelin, T.; Schulfter, K.; Kiiskinen, H.; Samela, J.; Bismarck, A., High Performance Cellulose Nanocomposites: Comparing the Reinforcing Ability of Bacterial Cellulose and Nanofibrillated Cellulose. ACS Applied Materials \& Interfaces 2012, 4, (8), 4078-4086.

30. Bergin, S. D.; Nicolosi, V.; Streich, P. V.; Giordani, S.; Sun, Z.; Windle, A. H.; Ryan, P.; Niraj, N. P. P.; Wang, Z.-T. T.; Carpenter, L.; Blau, W. J.; Boland, J. J.; Hamilton, J. P.; Coleman, J. N., Towards Solutions of Single-Walled Carbon Nanotubes in Common Solvents. Advanced Materials 2008, 20, (10), 1876-1881.

31. Hernandez, Y.; Nicolosi, V.; Lotya, M.; Blighe, F. M.; Sun, Z.; De, S.; McGovern, I. T.; Holland, B.; Byrne, M.; Gun'Ko, Y. K.; Boland, J. J.; Niraj, P.; Duesberg, G.; Krishnamurthy, S.; Goodhue, R.; Hutchison, J.; Scardaci, V.; Ferrari, A. C.; Coleman, J. N., 
High-yield production of graphene by liquid-phase exfoliation of graphite. Nature nanotechnology 2008, 3, (9), 563-8.

32. Cunningham, G.; Lotya, M.; Cucinotta, C. S.; Sanvito, S.; Bergin, S. D.; Menzel, R.; Shaffer, M. S. P.; Coleman, J. N., Solvent Exfoliation of Transition Metal Dichalcogenides: Dispersibility of Exfoliated Nanosheets Varies Only Weakly between Compounds. ACS Nano 2012, 6, (4), 3468-3480.

33. Gilkes, N. R.; Jervis, E.; Henrissat, B.; Tekant, B.; Miller, R. C.; Warren, R. A.; Kilburn, D. G., The adsorption of a bacterial cellulase and its two isolated domains to crystalline cellulose. Journal of Biological Chemistry 1992, 267, (10), 6743-6749.

34. Wypych, G., Handbook of Solvents. 2001.

35. Rubinstein, M.; Colby, R. H., Polymer Physics. First ed.; Oxford University Press: Oxford, 2003; p 440.

36. Lyklema, J., The surface tension of pure liquids: Thermodynamic components and corresponding states. Colloids and Surfaces A: Physicochemical and Engineering Aspects 1999, 156, (1-3), 413-421.

37. Hernandez, Y.; Lotya, M.; Rickard, D.; Bergin, S. D.; Coleman, J. N., Measurement of Multicomponent Solubility Parameters for Graphene Facilitates Solvent Discovery. Langmuir 2009, 26, (5), 3208-3213.

38. Coleman, J. N.; Lotya, M.; O’Neill, A.; Bergin, S. D.; King, P. J.; Khan, U.; Young, K.; Gaucher, A.; De, S.; Smith, R. J.; Shvets, I. V.; Arora, S. K.; Stanton, G.; Kim, H.-Y.; Lee, K.; Kim, G. T.; Duesberg, G. S.; Hallam, T.; Boland, J. J.; Wang, J. J.; Donegan, J. F.; Grunlan, J. C.; Moriarty, G.; Shmeliov, A.; Nicholls, R. J.; Perkins, J. M.; Grieveson, E. M.; Theuwissen, K.; McComb, D. W.; Nellist, P. D.; Nicolosi, V., Two-Dimensional Nanosheets Produced by Liquid Exfoliation of Layered Materials. Science 2011, 331, (6017), 568-571.

39. Yau, H. C.; Bayazit, M. K.; Steinke, J. H. G.; Shaffer, M. S. P., Sonochemical degradation of $\mathrm{N}$-methylpyrrolidone and its influence on single walled carbon nanotube dispersion. Chemical Communications 2015, 51, (93), 16621-16624.

40. Heng, J. Y. Y.; Pearse, D. F.; Thielmann, F.; Lampke, T.; Bismarck, A., Methods to determine surface energies of natural fibres: a review. Composite Interfaces 2007, 14, (7-9), 581-604.

41. Lavielle, L.; Schultz, J., Surface properties of carbon fibers determined by inverse gas chromatography: role of pretreatment. Langmuir 1991, 7, (5), 978-981.

42. Parthasarathi, R.; Bellesia, G.; Chundawat, S. P.; Dale, B. E.; Langan, P.; Gnanakaran, S., Insights into hydrogen bonding and stacking interactions in cellulose. The journal of physical chemistry. A 2011, 115, (49), 14191-202.

43. Ho, R.; Heng, J. Y. Y., A Review of Inverse Gas Chromatography and its Development as a Tool to Characterize Anisotropic Surface Properties of Pharmaceutical Solids. KONA Powder and Particle Journal 2013, 30, 164-180.

44. Menzel, R.; Bismarck, A.; Shaffer, M. S. P., Deconvolution of the structural and chemical surface properties of carbon nanotubes by inverse gas chromatography. Carbon 2012, 50, (10), 3416-3421.

45. Bailey, R. A.; Persaud, K. C., Application of inverse gas chromatography to characterisation of a polypyrrole surface. Analytica Chimica Acta 1998, 363, (2-3), 147-156.

46. Papirer, E.; Brendle, E.; Balard, H.; Vergelati, C., Inverse gas chromatography investigation of the surface properties of cellulose. Journal of Adhesion Science and Technology 2000, 14, (3), 321-337.

47. Lee, K.; Blaker, D.; Murakami, R.; Heng, J. Y. Y.; Bismarck, A., Phase Behavior of Medium and High Internal Phase Water-in-Oil Emulsions Stabilized Solely by Hydrophobized Bacterial Cellulose Nano fibrils. Langmuir 2014, 30, 452-460. 
48. Pommet, M.; Juntaro, J.; Heng, J. Y. Y.; Mantalaris, A.; Lee, A. F.; Wilson, K.; Kalinka, G.; Shaffer, M. S. P.; Bismarck, A., Surface Modification of Natural Fibers Using Bacteria: Depositing Bacterial Cellulose onto Natural Fibers To Create Hierarchical Fiber Reinforced Nanocomposites. Biomacromolecules 2008, 9, (6), 1643-1651.

49. Ylä-Mäihäniemi, P. P.; Heng, J. Y. Y.; Thielmann, F.; Williams, D. R., Inverse Gas Chromatographic Method for Measuring the Dispersive Surface Energy Distribution for Particulates. Langmuir 2008, 24, (17), 9551-9557.

50. Gindl, W.; Keckes, J., Drawing of self-reinforced cellulose films. Journal of Applied Polymer Science 2007, 103, (4), 2703-2708.

51. Retegi, A.; Gabilondo, N.; Peña, C.; Zuluaga, R.; Castro, C.; Gañan, P.; de la Caba, K.; Mondragon, I., Bacterial cellulose films with controlled microstructure-mechanical property relationships. Cellulose 2010, 17, (3), 661-669.

52. Yano, H.; Nakahara, S., Bio-composites produced from plant microfiber bundles with a nanometer unit web-like network. Journal of Materials Science 2004, 39, (5), 1635-1638.

53. Nakagaito, A. N.; Yano, H., Novel high-strength biocomposites based on microfibrillated cellulose having nano-order-unit web-like network structure. Appl Phys A 2005, 80, (1), 155-159.

54. Nakagaito, A. N.; Iwamoto, S.; Yano, H., Bacterial cellulose: the ultimate nano-scalar cellulose morphology for the production of high-strength composites. Appl Phys A 2005, 80, (1), 93-97.

55. Gibson, L. J.; Ashby, M. F., Cellular Solids: Structure and Properties. Cambridge University Press: 1997.

56. Qiu, L.; Liu, J. Z.; Chang, S. L. Y.; Wu, Y.; Li, D., Biomimetic superelastic graphenebased cellular monoliths. Nat Commun 2012, 3, 1241.

57. Blighe, F. M.; Lyons, P. E.; De, S.; Blau, W. J.; Coleman, J. N., On the factors controlling the mechanical properties of nanotube films. Carbon 2008, 46, (1), 41-47. 